\title{
Immunoglobulin and free light chain abnormalities in Gaucher disease type I: data from an adult cohort of 63 patients and review of the literature
}

\author{
M. de Fost • T. A. Out • F. A. de Wilde • E. P. M. Tjin • \\ S. T. Pals • M. H. J. van Oers • R. G. Boot • \\ J. F. M. G. Aerts • M. Maas • S. vom Dahl • \\ C. E. M. Hollak
}

Received: 21 November 2007 / Accepted: 22 December 2007 /Published online: 15 February 2008

(C) The Author(s) 2008

\begin{abstract}
Gaucher disease type I, the most common lysosomal storage disorder, is associated with immunoglobulin abnormalities. We studied the prevalence, risk factors, pathogenesis, and effect of enzyme relation therapy (ERT) on gammopathies in an adult Gaucher disease type I cohort $(N=63)$ and related the results to a review of the
\end{abstract}

M. de Fost • C. E. M. Hollak $(\bowtie)$

Department of Endocrinology and Metabolism, F4-279,

University of Amsterdam, Academic Medical Center,

P.O. Box 22700, 1100 DD Amsterdam, The Netherlands

e-mail: c.e.hollak@amc.uva.nl

T. A. Out $\cdot$ F. A. de Wilde

Department of Experimental Immunology,

Academic Medical Centre,

Amsterdam, The Netherlands

E. P. M. Tjin $\cdot$ S. T. Pals

Department of Pathology, Academic Medical Centre,

Amsterdam, The Netherlands

M. H. J. van Oers

Department of Haematology, Academic Medical Centre,

Amsterdam, The Netherlands

R. G. Boot • J. F. M. G. Aerts

Department of Medical Biochemistry, Academic Medical Centre, Amsterdam, The Netherlands

M. Maas

Department of Radiology, Academic Medical Centre,

Amsterdam, The Netherlands

S. vom Dahl

Department of Internal Medicine/Gastroenterology,

St Franziskus Hospital, Teaching Hospital, University of Cologne,

Köln, Germany currently available literature. Polyclonal gammopathies and monoclonal gammopathy of undetermined significance (MGUS) in our adult GD I cohort were found in $41 \%$ and $19 \%$ of patients. These results are similar to the data from the literature and correspond to the increased risk of multiple myeloma (MM) that has been described. The prevalence of MGUS in our cohort increased with age but was not associated with disease severity or exposure time. The serum levels of free light chains of immunoglobulins were measured and were not found predictive for the development of MGUS or MM. Levels of pro- as well as anti-inflammatory cytokines, growth factors, and chemokines, especially those involved in inflammation and B-cell function, are disturbed in GD I, with the most impressive and consisting elevations for interleukin-10 and pulmonary and activation-regulated chemokine. A beneficial effect of ERT on the occurrence and progression of gammopathies was suggested from longitudinal data.

Keywords Gaucher disease · MGUS · Multiple myeloma . Free light chains $\cdot$ Cytokines

\section{Introduction}

Gaucher disease type I (GD I, OMIM \#230800) is the most common lysosomal storage disorder. The disease is characterized by a deficiency of the lysosomal enzyme glucocerebrosidase (glucosylceramidase), which leads to the accumulation of glucocerebroside in macrophages. The lipid laden macrophages are called Gaucher cells and are mainly found in liver, spleen, and bone marrow, resulting in the most important clinical features hepatosplenomegaly, 
skeletal disease, and cytopenia [1, 2]. Since 1991, GD I can be effectively treated with recombinant glucocerebrosidase (enzyme replacement therapy, ERT, imiglucerase; Genzyme, Cambridge, MA, USA). More recently, substrate reduction therapy (miglustat, Actelion Pharmaceuticals, Basel, Switzerland) has been registered for more attenuated disease.

An associated feature of GD I is the high frequency of polyclonal and monoclonal gammopathies [3-22]. In the general population, polyclonal hypergammaglobulinemia is a common clinical finding, especially in the setting of chronic inflammation [23], resulting from an overproduction of immunoglobulins by plasma cells or B-lymphocytes. An abnormal increase of monoclonal immunoglobulins or fragments thereof (M protein) can be found in pre-malignant conditions such as MGUS (monoclonal gammopathy of undetermined significance) and malignancies of the B-cell lineage such as multiple myeloma (MM), primary amyloidosis, Waldenström macroglobulinemia, chronic lymphocytic leukemia, and B-cell lymphoma. MGUS is found in approximately $3.2 \%$ of adults over the age of 50 , increasing to $7.5 \%$ at the age of 85 [24]. Of these individuals, $1 \%$ per year shows progression to MM or a related malignancy. Accordingly, in GD I the risk of MM is strongly increased, as has been reported in recent studies [25-29]. The risk increases with advancing age $[19,26]$, but whether disease severity is a risk factor is currently unknown.

The mechanism explaining the relationship between GD and immunoglobulin abnormalities is far from understood. Studies have mainly focused on cytokines as the mediators between Gaucher cells, surrounding macrophages and B cells. Plasma levels of several pro-inflammatory cytokines, such as tumor necrosis factor (TNF)- $\alpha$, interleukin (IL)-1, and IL-6, as well as the anti-inflammatory IL-10, were found to be increased in GD to variable extents [4, 30-33]. IL-6 and IL-10, as well as hepatocyte growth factor (HGF), are also involved in the pathogenesis of MM [34]. Other interesting factors, known to be highly elevated in GD patients, are pulmonary and activation-regulated chemokine (PARC) [35], which is involved in initiating the adaptive immune response. Two studies have reported on the effect of ERT, with some decrease in polyclonal gammopathies [6] and a decline in monoclonal M-protein level in a single case [36].

A relatively new method to identify and monitor monoclonal gammopathies is by quantifying immunoglobulin free light chains (FLC), circulating $\mathrm{k}$ and $\lambda$ chains that are not bound to the immunoglobulin heavy chains, using a highly sensitive automated immunoassay [37-39]. An abnormal FLC ratio is an important independent risk factor for progression of MGUS to MM or a related disorder [40, 41]. In addition, measuring FLC is a sensitive additional tool to identify monoclonal gammopathies [42]. In GD I, in which the incidence of MGUS and MM is highly increased [26], the FLC assay may provide a useful diagnostic tool for early detection of MGUS and MM.

In this study, we present new data on the prevalence of polyclonal and monoclonal gammopathies from a large adult GD I cohort and review the currently available literature. Second, we studied whether age, disease severity, and exposure time are risk factors for the development of monoclonal gammopathies, and if this risk is subsequently decreased by the administration of ERT. In addition, for the first time, we investigated the role of FLC as a predictor of the development of monoclonal gammopathies in GD I. Finally, the pathogenesis of immunoglobulin abnormalities in GD patients was studied by means of pro- and antiinflammatory cytokine, chemokine, and growth factor levels and is discussed in relation to previous literature.

\section{Materials and methods}

Patients and study design

The files were reviewed and archived serum samples were collected of all adult GD type I patients that were known from the outpatient clinic for inherited metabolic disorders at the Academic Medical Centre (AMC), Amsterdam, The Netherlands $(N=63)$. The diagnosis GD was based on measurement of deficient glucocerebrosidase activity in leukocytes and genotyping [43]. Of the 63 patients, 50 received ERT according to an individualized dosing protocol [44] and two patients received substrate reduction therapy. Data on age, sex, splenectomy, genotype, severity score index, (SSI [45]), creatinine, urea, chitotriosidase, and the presence and type of immunoglobulin class of monoclonal proteins were collected. In patients with a monoclonal gammopathy, exposure time was defined as the number of years between the diagnosis GD I and the diagnosis monoclonal gammopathy or start of ERT, whichever came first. In patients without a monoclonal gammopathy, exposure time was calculated as the number of years between the diagnosis GD I and start of therapy, or, in patients not receiving therapy, the first visit to our clinic.

MGUS was defined as the presence of a monoclonal immunoglobulin component in the serum (as determined by protein electrophoresis in agar/agarose gels and immunofixation) at a concentration of less than $30 \mathrm{~g} / \mathrm{l}$ (IgG, IgA, or IgM) and normal serum calcium and creatinine [46]. Although histology is required to distinguish osteolytic lesions caused by MM from those caused by GD, we decided to classify long-existing lesions as being GD related. Bone marrow examinations were only performed when a previously unknown $\mathrm{M}$ protein was discovered or in case of a sharp rise in the levels of immunoglobulins or 
FLC. In case of MM, stage was determined according to the Durie-Salmon [47] and International Staging System (ISS) criteria [48].

We investigated whether levels of FLC could be predictive for the development of MGUS and whether these levels were related to disease severity. Therefore, we measured FLC levels in serum before start of enzyme replacement therapy in ten patients with mild GD $(\mathrm{SSI} \leq 8)$ and ten patients with severe GD (SSI $\geq 9)$, all without a monoclonal gammopathy.

In addition, we studied whether changes in cytokine levels and in FLC and immunoglobulins at baseline and during ERT were related to the presence or absence of a monoclonal gammopathy. Therefore, the group of patients with a monoclonal gammopathy was matched for age, sex, spleen status, SSI, and the use of ERT to a control group of GD patients without a monoclonal gammopathy. Serial measurements of levels of IL-6, IL-10, and PARC at baseline and after 12, 24, and a median of 114 months of ERT (range 40-143, whatever was the last determination) were performed. These were related to changes in immunoglobulins and free light chains. Hepatocyte growth factor (HGF) was measured only at baseline. One patient did not receive therapy; the first hospital visit was used as T0.

\section{Assays}

The standard enzyme activity assay for chitotriosidase with 4-MU-chitotriose (Sigma, St. Louis, MO, USA) as a substrate was performed at $\mathrm{pH} 5.2$ [49]. Serum $\kappa$ and $\lambda$ FLC were measured using FREELITE reagents (The Binding Site Ltd, Birmingham, England) on a BNII nephelometer (Dade-Behring, Deerfield, IL, USA) [3739]. Monoclonal FLC were identified as values for $k$ or $\lambda$ that exceeded the reference ranges $(\kappa \quad 6.2-30.2 \mathrm{mg} / \mathrm{l}, \lambda$ 9.1-40 mg/l) and produced an abnormal $\mathrm{k} / \lambda$ ratio $(<0.3$ or >1.57). Elevated concentrations of FLC without an abnormal $\mathrm{k} / \lambda$ ratio indicate a polyclonal or oligoclonal increase of FLC. Levels of IgG, IgA, and IgM were measured by immunoturbidimetric assay (Roche Tinaquant). IL-6, IL-10, HGF, and PARC were measured by specific enzyme-linked immunosorbent assays (ELISAs), according to the instructions of the manufacturer (IL-6 and IL-10: Sanquin, Amsterdam, The Netherlands; HGF: R\&D Systems, Minneapolis, MN, USA; PARC: Biosource International, Camarillo, CA, USA).

\section{Statistics}

Values in patients are given as medians and ranges. Differences between patient groups were analyzed by the Mann-Whitney $U$ test or by $\chi$-square test. Linear mixed models were used to assess longitudinal changes. Correla- tions were tested by the rank-correlation test (Spearman coefficient, $\rho$ ). $P<0.05$ was considered to represent a statistical difference.

\section{Search strategy}

To compare the prevalence of poly- and monoclonal gammopathies in our cohort with earlier case series and to study the relative risk of $\mathrm{MM}$, we performed a MEDLINE search combining the MESH terms Gaucher disease with either hypergammaglobulinemia, paraproteinemias, and/or multiple myeloma. Literature on cytokines, chemokines, and growth factors in relation to the development of immunoglobulin abnormalities in GD were searched combining the MESH terms Gaucher disease with cytokines and/or chemokines. Case reports were excluded and only studies that included at least ten patients were selected.

\section{Results}

\section{Patients}

The 63 patients had a median age of 53 years (range 2583). Thirty-two of patients (51\%) were men, and $23(37 \%)$ were splenectomized. At baseline, median SSI was 8 (range 3-19). The majority of patients had a genotype containing N370S (95\%), with N370S/L444P being the most common combination $(40 \%)$. All patients had creatinine and urea values within the normal range.

At the first assessment, 24 (38\%) patients had normal immunoglobulin levels, 26 (41\%) patients had a polyclonal gammopathy, $12(19 \%)$ patients had MGUS, and one patient had MM (Table 1, \#2). During follow-up (range 5-16 years), none of the patients with normal immunoglobulin levels or a polyclonal gammopathy developed a monoclonal gammopathy.

Of the 12 patients with MGUS, two developed MM and/ or amyloidosis after approximately 2 years of ERT (\#1 and 3). Patient \#1 was diagnosed with MM and amyloidosis 25 months after start of ERT. Pulse therapy with dexamethasone was started. Three months after the diagnosis the patient died from cardiac failure. At 24 months after start of ERT, patient \#3 was diagnosed with amyloidosis. She received melphalan and prednisone, but died 12 months later from cardiac failure. Patient \#2 was diagnosed with MM stage IA before start of ERT. During follow-up, IgG levels gradually increased. After 7 years of ERT, treatment with reduced dose melphalan and prednisone was started, which resulted in unacceptable cytopenia. Subsequently, thalidomide, $100 \mathrm{mg}$ daily, was started with beneficial effect and stable disease parameters for the last 3 years. 
Table 1 Characteristics of Gaucher disease type I patients with a monoclonal gammopathy
$M$ Male, $F$ female, $S x$ splenectomy, ERT enzyme replacement therapy, $M G$ monoclonal gammopathy, $M M$ multiple myeloma, MGUS monoclonal gammopathy of undetermined significance, $I g$ immunoglobulin

\begin{tabular}{|c|c|c|c|c|c|c|}
\hline $\begin{array}{l}\text { Patient } \\
\text { no. }\end{array}$ & Sex & $\mathrm{Sx}$ & $\begin{array}{l}\text { Age in } 2007 \text { or at } \\
\text { death }\end{array}$ & Therapy & MG type & Ig type \\
\hline 1 & M & $\mathrm{N}$ & 55 & ERT & $\begin{array}{l}\text { MGUS, progression to } \\
\text { amyloidosis and MM }\end{array}$ & Free $k$ \\
\hline 2 & M & $\mathrm{Y}$ & 71 & ERT & $\mathrm{MM}$ & IgGK \\
\hline 3 & $\mathrm{~F}$ & $\mathrm{~N}$ & 46 & ERT & $\begin{array}{l}\text { MGUS, progression to } \\
\text { amyloidosis }\end{array}$ & $\operatorname{IgG} \lambda$ \\
\hline 4 & M & $\mathrm{Y}$ & 60 & ERT & MGUS & IgGK \\
\hline 5 & M & $\mathrm{Y}$ & 67 & ERT & MGUS & $\operatorname{IgG} \lambda$ \\
\hline 6 & M & $\mathrm{Y}$ & 59 & ERT & MGUS & $\operatorname{IgA} \lambda, \operatorname{IgGK}$ \\
\hline 7 & $\mathrm{~F}$ & $\mathrm{~N}$ & 67 & ERT & MGUS & $\operatorname{IgAk}$ \\
\hline 8 & M & $\mathrm{N}$ & 56 & ERT & MGUS & $\operatorname{IgG} \lambda$ \\
\hline 9 & M & $\mathrm{Y}$ & 65 & ERT & MGUS & 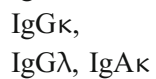 \\
\hline 10 & M & $\mathrm{N}$ & 56 & ERT & MGUS & $\begin{array}{l}\operatorname{IgM\kappa } \\
\operatorname{IgM} \lambda\end{array}$ \\
\hline 11 & $\mathrm{~F}$ & $\mathrm{~N}$ & 63 & No & MGUS & $\operatorname{IgG} \lambda, \operatorname{IgM} \kappa$ \\
\hline 12 & $\mathrm{~F}$ & $\mathrm{Y}$ & 75 & ERT & MGUS & IgGK \\
\hline 13 & M & $\mathrm{N}$ & 51 & ERT & MGUS & $\operatorname{IgG} \lambda$ \\
\hline
\end{tabular}

Of the ten remaining patients with non-progressive MGUS, six had a monoclonal, three had a biclonal, and one a triclonal gammopathy. The most common immunoglobulin type was IgGK (Table 1; results previously presented in part in [26]).

Patients with a monoclonal gammopathy were significantly older than patients without a monoclonal gammopathy (Table 2). Exposure time to GD, defined as time from diagnosis until first assessment at our clinic, and severity of disease measures, assessed by SSI and chitotriosidase at baseline, were comparable.

A search for studies on monoclonal and polyclonal gammopathies in GD I resulted in five series [4, 6, 16, 19, 21]. Polyclonal gammopathies were reported in $14-64 \%$ and monoclonal gammopathies in $1-35 \%$ of GD I patients (Table 3).

Five studies have described the prevalence and/or relative risk of $\mathrm{MM}$ in GD patients [25-29]. Table 4

Table 2 Baseline characteristics of Gaucher type I patients with a monoclonal gammopathy vs patients without a monoclonal gammopathy

\begin{tabular}{llll}
\hline & Without MG & With MG & $P$ \\
\hline No. of patients & 50 & 13 & \\
Age in 2007 or at death & $51(25-83)$ & $60(46-75)$ & 0.003 \\
No. of male patients & $23(46 \%)$ & $9(69 \%)$ & $\mathrm{NS}$ \\
Years of exposure & $11(0-37)$ & $18(1-44)$ & $\mathrm{NS}$ \\
No. of splenectomies & $17(34 \%)$ & $6(46 \%)$ & $\mathrm{NS}$ \\
SSI at baseline & $7(3-19)$ & $12(4-16)$ & $\mathrm{NS}$ \\
Chitotriosidase & $16,703(5,409-$ & $22,534(6,417-$ & $\mathrm{NS}$ \\
(nmol/ml h) at baseline & $132,199)$ & $62,122)$ & \\
\hline
\end{tabular}

Data reflect absolute numbers (and percentage) or median (and range). $M G$ Monoclonal gammopathy, NS not significant, SSI severity score index summarizes the data from these studies. The frequency of $\mathrm{MM}$ in these cohorts was $0.4-4.0 \%$, with significantly elevated relative risks of 5.9-51.1.

Immunoglobulin and FLC levels

In 20 GD patients from the Dutch cohort without a monoclonal gammopathy (ten with mild disease, $\mathrm{SSI} \leq 8$, and ten with severe disease, SSI $\geq 9$ ), FLC were measured before start of therapy (Fig. 1a). One patient was found to have a slightly abnormal ratio, and six patients had an increase in one or both FLC, with a normal ratio. There were no significant differences in $\mathrm{k}$ or $\lambda$ FLC-levels

Table 3 Studies on the prevalence of monoclonal and polyclonal gammopathies in type I Gaucher disease

\begin{tabular}{cllll}
\hline Reference & $\begin{array}{l}\text { No. of } \\
\text { Gaucher } \\
\text { patients }\end{array}$ & Age & $\begin{array}{l}\text { Polyclonal } \\
\text { gammopathies }\end{array}$ & $\begin{array}{l}\text { Monoclonal } \\
\text { gammopathies }\end{array}$ \\
\hline $\begin{array}{c}\text { de Fost } \\
\text { et al. [26] }\end{array}$ & 63 & $25-83$ & $26(41 \%)$ & $12(19 \%)$ \\
$\begin{array}{c}\text { Pratt } \\
\text { et al. [19] }\end{array}$ & 16 & $9-70$ & $6(38 \%)$ & $4(25 \%)$ \\
$\begin{array}{c}\text { Shoenfeld } \\
\text { et al. [21] }\end{array}$ & 25 & $24-78$ & $15(60 \%)$ & $2(8 \%)$ \\
$\begin{array}{c}\text { Marti } \\
\text { et al. [16] }\end{array}$ & 23 & $41.8 \pm 18$ & $10(43 \%)$ & $8(35 \%)$ \\
$\begin{array}{c}\text { Allen } \\
\text { et al. [4] }\end{array}$ & 22 & $23-65$ & $14(64 \%)$ & $3(14 \%)$ \\
$\begin{array}{c}\text { Brautbar } \\
\text { et al. [6] }\end{array}$ & 507 & $16-81$ & $14-25 \%$ & $5(1 \%)$ \\
\hline
\end{tabular}

Data reflect absolute numbers (and percentage), or, in the study of Marti et al., mean \pm standard deviation. 
Table 4 Studies on the prevalence and relative risk of multiple myeloma in type I Gaucher disease

\begin{tabular}{lllllll}
\hline Reference & $\begin{array}{l}\text { No. of } \\
\text { patients }\end{array}$ & $\begin{array}{l}\text { Ethnic } \\
\text { background }\end{array}$ & Age & $\begin{array}{l}\text { Control } \\
\text { group }\end{array}$ & $\begin{array}{l}\text { No. of patients } \\
\text { with MM }\end{array}$ & RR of MM \\
\hline de Fost et al. [26] & 131 & Mixed & $50 \pm 14$ & Dutch Cancer Registry & $2(1.5 \%)$ & $51.1(95 \%$ CI: 6.2-184) \\
Lee [25] & 239 & Mixed & Not given & None & $5(2 \%)$ & ND \\
Shiran et al. [28] & 48 & Jewish & $54 \pm 20$ & 511 individuals from the same region & $2(4 \%)$ & ND \\
Zimran et al. [29] & 505 & Jewish & $38 \pm 21$ & Israeli Cancer Registry & $2(0.4 \%)$ & ND \\
Rosenbloom et al. [27] & 2,510 & Mixed & 33 & US Cancer Registry & $10(0.4 \%)$ & $5.9(95 \%$ CI: 2.8-10.8) \\
\hline
\end{tabular}

Data on age reflect mean \pm standard deviation; data on number of patients with multiple myeloma reflect absolute numbers (and percentage). $M M$ Multiple myeloma, $R R$ relative risk, $95 \%$ CI 95\% confidence interval, $N D$ not done

between patients with severe- and patients with mild GD I. During follow-up (range 10-16 years), none of the patients developed a monoclonal gammopathy.

FLC levels were measured in all GD I patients with a monoclonal gammopathy (Table 1, \#1-13) and matched GD I controls (\#co1-co13). No serum was available of patient \#12, resulting in two groups of 12 patients. Baseline immunoglobulin levels were not available in one patient with a monoclonal gammopathy (\#11) and five patients from the control group (\#co4, \#co5, \#co7, \#co11, and \#co13). At baseline, the patients who already had or would develop MM and/or amyloidosis (\#1-3) had strongly abnormal FLC $\kappa / \lambda$ ratios (Fig. 1b). Of the nine patients with MGUS, one (\#7) had an abnormal FLC $\kappa / \lambda$ ratio and four showed elevated levels of FLC $\kappa$ or $\lambda$, but with a normal FLC ratio. The remaining four patients with MGUS had both FLC levels as well as a FLC $\kappa / \lambda$ ratio within the normal range. Six of the patients from the control group had FLC levels and a FLC $\kappa / \lambda$ ratio within the normal range, and six had elevated levels of one or both chains of
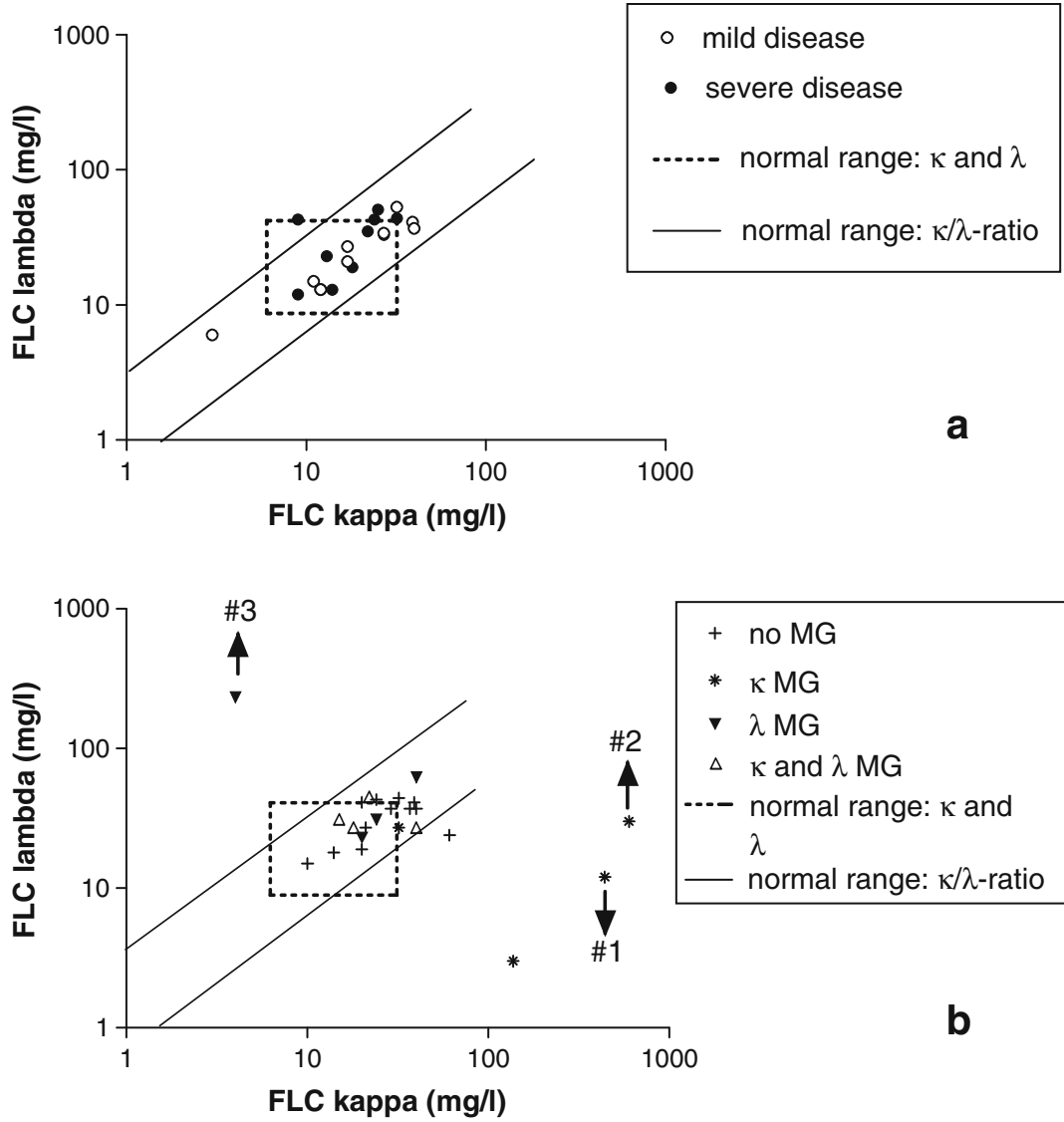

gammopathy and matched Gaucher disease controls (b). $M G$ Monoclonal gammopathy. The normal range for $\mathrm{k}$ was $6.2-30.2 \mathrm{mg} / \mathrm{l}$ and for $\lambda$ was $9.1-40 \mathrm{mg} / \mathrm{l}$. The normal ratio for $\mathrm{k} / \lambda$ was $0.3-1.57$

Fig. 1 FLC levels in Gaucher disease type I patients without a monoclonal gammopathy with mild disease $(\mathrm{SSI} \leq 8)$ and severe disease $(\mathrm{SSI} \geq 9)(\mathbf{a})$. FLC levels in Gaucher disease patients with a monoclonal 
whom only one (\#co6) patient showed an abnormal FLC $\kappa / \lambda$ ratio. During follow-up (range 6-15 years), none of the patients from the control group developed a monoclonal gammopathy.

Cytokines, chemokines, and growth factors

At baseline, IL-6 levels were within the normal range in all but four patients (Fig. 2). There was no significant difference in IL-6 levels between patients with or without a monoclonal gammopathy (median (range) $5.9 \mathrm{pg} / \mathrm{ml}$ (1.2-118.4) and $2.2 \mathrm{pg} / \mathrm{ml}(1.0-57.2)$, respectively). The majority of patients (17/24) showed elevated IL-10 levels, especially in the group of patients with a monoclonal gammopathy, although not significantly different from the patients without a monoclonal gammopathy $(17.1 \mathrm{pg} / \mathrm{ml}$ (3.9-419.8) and $6.9 \mathrm{pg} / \mathrm{ml}$ (1.4-299.3), respectively, $P=$ $0.2)$. PARC levels were elevated in all GD patients, without a difference between patients with or without a monoclonal gammopathy $(1,400.0 \mathrm{pg} / \mathrm{ml}(348.9-2817.3)$ and 1,078 pg/ $\mathrm{ml}$ (411.4-3,552.0), respectively). HGF was within the normal range in most (16/22) patients, without a difference between patients with or without a monoclonal gammopathy $(1,751 \mathrm{pg} / \mathrm{ml}(926-4,791)$ and $936 \mathrm{pg} / \mathrm{ml}(424-9,382)$, respectively).

A literature search resulted in seven studies on cytokines, chemokines, and growth factors in GD I patients (Table 5). In one of these studies, mRNA levels were measured [32], while in the remaining studies, plasma levels were studied. If possible, the number of patients with cytokine levels exceeding the reference range was determined. In studies in which normal ranges were not provided $[4,32]$, we defined the normal range as mean $\pm 2 \mathrm{SD}$ based on the values of the control group. This was not possible in the study of Barak et al. [30], in which no detailed data were provided.
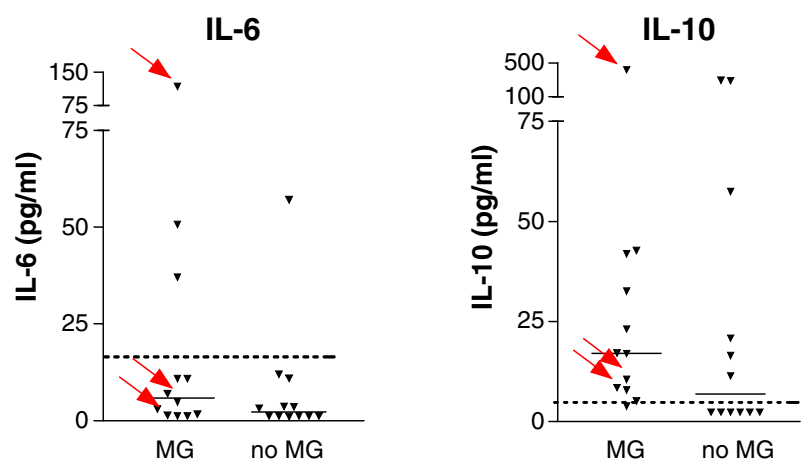

Fig. 2 Baseline levels of IL-6, IL-10, PARC, and HGF in Gaucher disease patients with a monoclonal gammopathy and matched Gaucher disease controls. Patients with multiple myeloma and/or amyloidosis are marked by an arrow. Dotted lines reflect the upper
Longitudinal changes

In general, at no time point was there a statistically significant difference in plasma levels of any of the factors (i.e., IgG, IgA, IgM, FLC $\kappa$ and $\lambda$, IL-6, IL-10, and PARC) between patients with and patients without a monoclonal gammopathy (Fig. 3). In addition, using mixed model analysis, in neither of the two patient groups, a significant decrease or increase could be established in plasma levels of any of the measured factors. The only exception was PARC, which decreased in all patients, except for one patient who did not use therapy (\#11). Changes in PARC levels could not be related to changes in levels of immunoglobulins or free light chains. There were no strong correlations (i.e., rho $>0.6$ ) between any of the factors.

More specifically, immunoglobulin levels remained stable or decreased in all patients, except for patient \#11, who showed an increase in IgM. This patient was different from other MGUS patients because she did not receive therapy. Free light chain levels were more variable, but clearly FLC levels of patients who were to develop or already suffered from $\mathrm{MM}$ and/or amyloidosis remained high during ERT (\#1-3). Although in most patients no trends could be distinguished, a consistent decrease in free light chains and immunogobulins was seen for example in patient 7 , who had an IgAK M protein. This patient responded very well to ERT, but other patients with excellent clinical responses did not always show a similar decrease in M-protein levels. No relationship was found between clinical response and decrease in either levels of immunoglobulins or FLCs.

The course of cytokines did not show a relationship with changes in either FLC or immunoglobulin levels, although in the untreated patient with increasing levels of $\operatorname{IgM}(\# 11)$, also an increase in IL-6 and PARC was noted. On the contrary, a spontaneous decrease in IL- 6 was found in
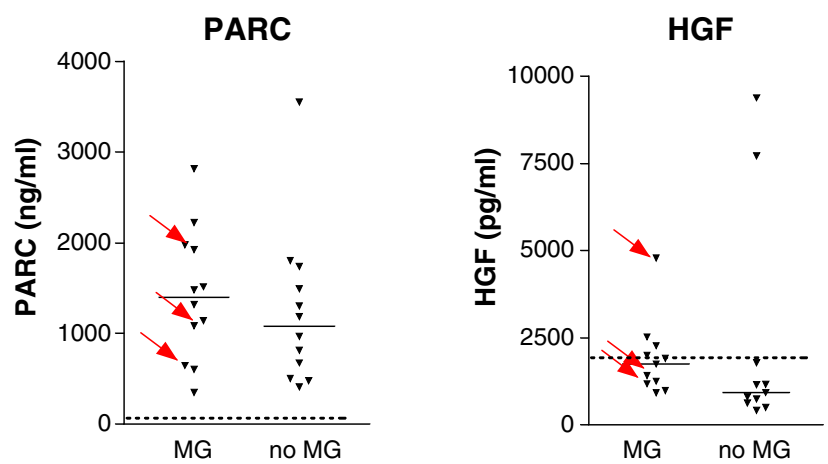

limit of the normal range. IL Interleukin, $H G F$ hepatocyte growth factor, $P A R C$ pulmonary and activation-regulated chemokine, $M G$ monoclonal gammopathy 
Table 5 Studies on plasma levels of cytokines, chemokines, and growth factors in Gaucher type I patients

\begin{tabular}{|c|c|c|c|c|c|}
\hline Reference & $\begin{array}{l}\text { No. of GD } \\
\text { I patients }\end{array}$ & Age & Cytokines & $\begin{array}{l}\text { Results, no. of patients (\%) } \\
\text { with elevated levels }\end{array}$ & $\begin{array}{l}P \text { value for difference with } \\
\text { mean values of the control group }\end{array}$ \\
\hline de Fost et al. [26] & 22 & $25-83$ & $\begin{array}{l}\text { IL-6 } \\
\text { IL-10 } \\
\text { PARC } \\
\text { HGF }\end{array}$ & $\begin{array}{l}4 / 24(17 \%) \\
17 / 24(71 \%) \\
24 / 24(100 \%) \\
6 / 22(27 \%)\end{array}$ & ND \\
\hline Michelakakis [33] & 25 & NG & TNF- $\alpha$ & $16 / 25(64 \%)$ & ND \\
\hline Allen et al. [4] & 22 & $23-65$ & $\begin{array}{l}\text { IL-1 } \beta \\
\text { TNF- } \alpha \\
\text { IL-6 } \\
\text { IL-10 }\end{array}$ & $\begin{array}{l}\text { Not detectable } \\
4 / 11(36 \%) \\
19 / 22(86 \%) \\
13 / 13(100 \%)\end{array}$ & $\begin{array}{l}\text { NS } \\
\text { NS } \\
P=0.0001 \\
P<0.0001\end{array}$ \\
\hline Lichtenstein et al. [32] & 18 & NG & $\begin{array}{l}\text { IL-1 } \beta \text { mRNA } \\
\text { TNF- } \alpha \text { mRNA } \\
\text { IL-6 mRNA } \\
\text { IL-8 mRNA }\end{array}$ & $\begin{array}{l}5 / 19(26 \%) \\
2 / 19(11 \%) \\
3 / 19(16 \%) \\
3 / 19(16 \%)\end{array}$ & $\begin{array}{l}P=0.0337 \\
\mathrm{NS} \\
\mathrm{NS} \\
\mathrm{NS}\end{array}$ \\
\hline Hollak et al. [31] & 29 & $16-66$ & $\begin{array}{l}\text { M-CSF } \\
\text { sCD14 } \\
\text { IL-8 } \\
\text { IL-6 } \\
\text { TNF- } \alpha\end{array}$ & $\begin{array}{l}24 / 28(86 \%) \\
25 / 27(93 \%) \\
25 / 27(93 \%) \\
0 / 27(0 \%) \\
0 / 27(0 \%)\end{array}$ & $\begin{array}{l}P<0.001 \\
P<0.0005 \\
P<0.0005 \\
\text { NS } \\
\text { NS }\end{array}$ \\
\hline Barak et al. [30] & 21 & $5-39$ & $\begin{array}{l}\text { IL-1 } \beta \\
\text { IL-1RA } \\
\text { sIL-2R } \\
\text { IL-6 } \\
\text { IL-8 } \\
\text { TNF- } \alpha\end{array}$ & $\begin{array}{l}\text { Mean levels elevated } \\
\text { Mean levels elevated } \\
\text { Mean levels elevated } \\
\text { Mean levels elevated } \\
\text { Not elevated } \\
3 / 21(14 \%)\end{array}$ & $\begin{array}{l}P=0.01 \\
P=0.01 \\
P<0.001 \\
P<0.01 \\
\text { NS } \\
\text { NS }\end{array}$ \\
\hline Boot et al. [35] & 55 & $12-67$ & PARC & $55 / 55(100 \%)$ & $P<0.0001$ \\
\hline Altarescu et al. [56] & 12 & $11-67$ & TNF- $\alpha$ & $1 / 12(8 \%)$ & NS \\
\hline
\end{tabular}

$N G$ Not given, $N D$ not done, $N S$ not significant

patient \#2, without therapy for his MM. In patient \#1, IL-10 showed a clear decrease after start of ERT but before the diagnosis amyloidosis and MM was made.

\section{Discussion}

In addition to the classical symptoms of GD I, such as hepatosplenomegaly, skeletal disease, and cytopenia, there is increasing evidence for existence of co-morbidities, including increased risk of cancer and abnormal immunoglobulin profiles. In fact, polyclonal gammopathies and MGUS occurred in $41 \%$ and $19 \%$, respectively, of our adult Gaucher cohort, which is in line with findings from the literature $(14-64 \%$ and $1-35 \%$ of patients $[4,6,16,19$, 21]). In addition, we established that the relative number of biclonal (3/10) and triclonal (1/10) gammopathies within the MGUS patients was especially high considering that in general, biclonal gammopathies occur in 3\% of subjects with MGUS [24], while triclonal gammopathies occur only very sporadically [50]. The types of immunoglobulin heavy and light chain immunoglobulins were comparable to the findings for MGUS in a non-GD population, with a predominance of $\operatorname{IgGK}$ [24]. As in the general population, the prevalence of MGUS in our cohort increased with age, but there was no relationship with disease severity measures, as assessed by exposure time, baseline SSI, and chitotriosidase levels. A relationship with age was first suggested by Pratt et al. [19], who investigated 16 patients aged 9 to 70 years and established an MGUS in four patients, all being over 50 years of age. Indirectly, he also showed an association with severity of disease, since all patients with splenomegaly had either a monoclonal or polyclonal gammopathy.

Considering the relatively high risk of monoclonal gammopathies in GD, the question was raised whether sensitive measuring of FLC would be useful for the early detection of monoclonal gammopathies in GD I patients. In a non-GD population, MGUS patients showed an abnormal FLC ratio in $44 \%$ of cases, which was an important risk factor for progression to $\mathrm{MM}$ or a related disorder [40, 41]. We found that the three GD patients who had or would soon develop a B-cell malignancy could easily be identified by their strongly abnormal FLC $\kappa / \lambda$ ratios. It was however, not possible to identify GD patients with MGUS on the basis of abnormal FLCs since $44 \%$ of GD patients with 

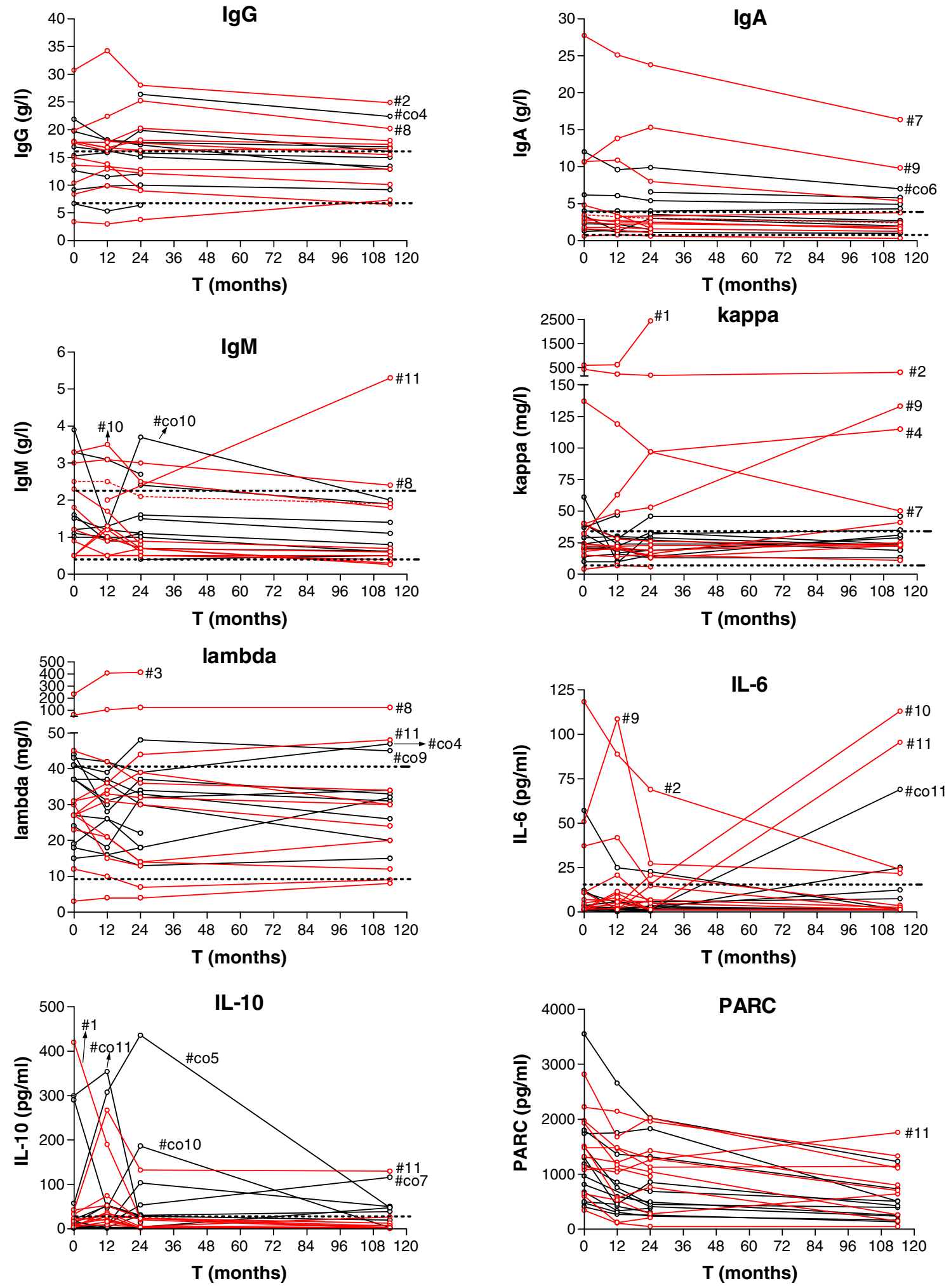

Fig. 3 Longitudinal changes in plasma levels of immunoglobulin heavy and free light chains, IL-6, IL-10, and PARC. Dotted lines reflect the normal range. Numbers reflect Gaucher disease patients with a monoclonal gammopathy as described in Table 1 (\#1-13) and

matched Gaucher disease controls (\#co1-co13) without a monoclonal gammopathy. IL Interleukin, PARC pulmonary and activation-regulated chemokine 
MGUS had both FLC levels as well as a FLC $k / \lambda$ ratio within the normal range. A slightly abnormal ratio was not predictive for progression to MM or MGUS in the single patient without a monoclonal gammopathy, even after 15 years of follow-up. None of the patients had a decrease in renal function, implicating that any FLC increase was indeed due to increased production by plasma cells.

MGUS patients are at risk for developing MM at a rate of $1 \%$ of patients per year. Accordingly, the prevalence of MM in GD I cohorts of $0.4-1.5 \%$ clearly exceeds the general prevalence of $0.02 \%$ (deduced from The Surveillance, Epidemiology, and End Results (SEER) Program of the National Cancer Institute (NCI)). The assumed diversity in relative risk of developing MM (5.9 and 51.1) can simply be explained by age differences in the cohorts: the highest number of MM patients was clearly established in the highest age groups.

In a recent consensus report on hematological manifestations of Gaucher disease, the higher incidence of multiple myeloma in Gaucher disease is acknowledged, and it is recommended that Gaucher patients should have their immunoglobulin profile determined at diagnosis and monitored every 2 years (patients $<50$ years) or every year (patients $>50$ years) [51].

Hypotheses on the pathogenesis of immunoglobulin disorders in GD have mainly focused on the accumulated glucocerebroside as the causative agent for chronic stimulation of macrophages surrounding Gaucher cells. Cytokines of macrophagic origin could in turn stimulate B cells, leading to a polyclonal gammopathy which may eventually transform, directly or via MGUS, into MM. Interestingly, plasma cells can be found in close contact with Gaucher cells, suggestive of local interaction (Fig. 4).

In our study, we measured IL-6, IL-10, and HGF, three factors important for differentiation and/or proliferation of

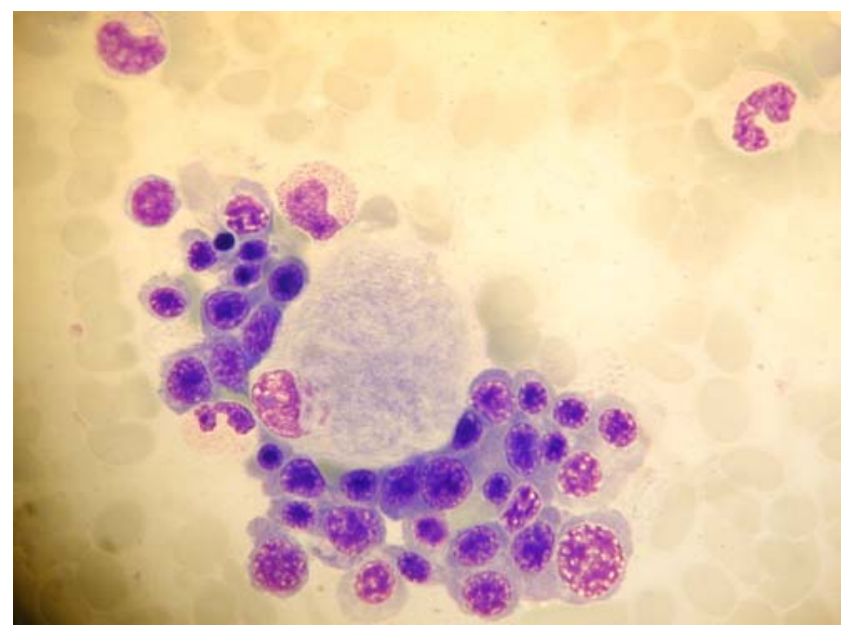

Fig. 4 Bone marrow aspirate showing plasma cells surrounding a Gaucher cell in a patient with Gaucher disease type I and multiple myeloma plasma cells. In addition, IL-6 and IL-10 are also involved in inflammation and in abnormal bone remodeling in $\mathrm{MM}$, aspects that are also present in GD. We found elevated IL10 levels in most patients, especially those with a monoclonal gammopathy, and predominantly normal levels of IL-6 and HGF. Previous studies have also described increased IL-10 levels [4]. However, findings on IL-6 in GD I have been variable [4, 30-32]. Inconsistent results have also been reported for the pro-inflammatory cytokines TNF- $\alpha$ and IL-1 $\beta$ and the chemokine IL- $8[4,30-33,52]$. Although not included in this study, increases have been described for the growth factor M-CSF (monocyte/macrophage-colony stimulating factor), the monocyte/macrophage activation marker sCD14 (soluble CD14) [31], sIL-2R (soluble IL-2 receptor), and IL-1RA (IL-1 receptor antagonist) [30]. The most impressive increase, both in our study as well in as in the study by Boot et al. [35], has been found for PARC, a chemokine that is assumed to be involved in B-cell differentiation by recruiting $\mathrm{T}$ cells and $\mathrm{CD}-38$ negative mantle zone B lymphocytes to antigen-presenting cells.

In addition to the in vivo studies, it has been described that murine macrophages that were stimulated in vitro by glucocerebroside release the pro-inflammatory lymphocyteactivating factor $(\mathrm{LAF}=\mathrm{IL}-1)$ in a dose-responsive manner. This effect was not seen on incubation with galactocerebroside, sphingomyelin, and ceramidetrihexoside [53]. Possibly, only minor glycolipid accumulation is sufficient for the development of B-cell derangement. In fact, a glucocerebrosidase deficient mouse (L444P homozygote) showed evidence of B-cell proliferation, as well as elevated serum IgG levels, even though storage cells were not found [54].

The heterogeneity in plasma cytokine levels that have been found could be explained by differences in patient populations and cytokine assays. In addition, it is not known whether plasma levels adequately reflect tissue levels. Nevertheless, clearly both pro- as well as antiinflammatory cytokine levels are disturbed in GD I. It is unlikely that Gaucher cells directly induce inflammation, since Gaucher cells have a phenotype resembling antiinflammatory alternatively activated macrophages. More likely, pro-inflammatory cytokines are produced by surrounding macrophages, with Gaucher cells compensating for the inflammatory compounds [55].

Now that it is generally accepted that ERT effectively reduces hepatosplenomegaly, cytopenia and skeletal disease, the focus should be shifted to new challenges, including the prevention and treatment of Gaucher associated co-morbidities. Novel data from our study suggest a beneficial effect of ERT on the occurrence and severity of gammopathies in GD patients. First, none of the patients developed MGUS during ERT. We did see progression of MGUS to amyloidosis and MM in two patients. However, since both patients developed these diseases relatively 
shortly after start of ERT, one could envision that irreversible changes leading to malignant transformation had already taken place, and could not be corrected by ERT. Second, we found that immunoglobulin levels either decreased or remained stable in both patients with and without a monoclonal gammopathy. The only patient with a strong increase in immunoglobulins (IgM) was a patient not using ERT. A clear influence of ERT on levels of FLC, IL6 , and IL-10 was not found in our study. A previous report also found a decrease in immunoglobulin levels during ERT, although only in patients with a polyclonal gammopathy, and not in patients with a monoclonal gammopathy [6]. Decreases in the levels of IL-10 [4], M-CSF, sCD1431, and PARC [35] have been described. Nevertheless, to draw firm conclusions on a possible positive effect of ERT on gammopathies in GD I, our presumptions should be confirmed in larger studies. This would require an international multicenter effort that should aim to establish whether indeed these long-term complications can be prevented by ERT and whether this would justify the early start of treatment.

In summary, there is a high prevalence in GD I of both polyclonal as well as monoclonal gammopathies, including MM. The risk of these diseases increases with age. Mechanisms causing gammopathies remain to be elucidated, but include the disturbance of cytokine levels involved in inflammation and B-cell function. ERT is likely to have a beneficial effect in preventing the occurrence and the progression of gammopathies.

Open Access This article is distributed under the terms of the Creative Commons Attribution Noncommercial License which permits any noncommercial use, distribution, and reproduction in any medium, provided the original author(s) and source are credited.

\section{References}

1. Brady RO, Kanfer JN, Shapiro D (1965) Metabolism of glucocerebrosides. II. Evidence of an enzymatic deficiency in Gaucher's disease. Biochem Biophys Res Commun 18:221-225

2. Patrick AD (1965) Short communications: a deficiency of glucocerebrosidase in Gaucher's disease. Biochem J 97:17C-18C

3. Airo R, Gabusi G, Guindani M (1993) Gaucher's disease associated with monoclonal gammopathy of undetermined significance: a case report. Haematologica 78:129-131

4. Allen MJ, Myer BJ, Khokher AM, Rushton N, Cox TM (1997) Pro-inflammatory cytokines and the pathogenesis of Gaucher's disease: increased release of interleukin-6 and interleukin-10. QJM 90:19-25

5. Benjamin D, Joshua H, Djaldetti M, Hazaz B, Pinkhas J (1979) Nonsecretory IgD-kappa multiple myeloma in a patient with Gaucher's disease. Scand J Haematol 22:179-184

6. Brautbar A, Elstein D, Pines G, Abrahamov A, Zimran A (2004) Effect of enzyme replacement therapy on gammopathies in Gaucher disease. Blood Cells Mol Dis 32:214-217
7. Chang-Lo M, Yam LT, Rubenstone AI, Schwartz SO (1975) Gaucher's disease associated with chronic lymphocytic leukaemia, gout and carcinoma. J Pathol 116:203-207

8. Dikman SH, Goldstein M, Kahn T, Leo MA, Weinreb N (1978) Amyloidosis. An unusual complication of Gaucher's disease. Arch Pathol Lab Med 102:460-462

9. Fox H, McCarthy P, Andre-Schwartz J, Shoenfeld Y, Miller KB (1984) Gaucher's disease and chronic lymphocytic leukemia. Possible pathogenetic link between Gaucher's disease and B-cell proliferations? Cancer 54:312-314

10. Garfinkel D, Sidi Y, Ben Bassat M et al (1982) Coexistence of Gaucher's disease and multiple myeloma. Arch Intern Med 142:2229-2230

11. Hanash SM, Rucknagel DL, Heidelberger KP, Radin NS (1978) Primary amyloidosis associated with Gaucher's disease. Ann Intern Med 89:639-641

12. Harder H, Eucker J, Zang C et al (2000) Coincidence of Gaucher's disease due to a $1226 \mathrm{G} / 1448 \mathrm{C}$ mutation and of an immunoglobulin G lambda multiple myeloma with Bence-Jones proteinuria. Ann Hematol 79:640-643

13. Hrebicek M, Zeman J, Musilova J et al (1996) A case of type I Gaucher disease with cardiopulmonary amyloidosis and chitotriosidase deficiency. Virchows Arch 429:305-309

14. Kaloterakis A, Filiotou A, Koskinas J et al (1999) Systemic AL amyloidosis in Gaucher disease. A case report and review of the literature. J Intern Med 246:587-590

15. Mark T, Dominguez C, Rywlin AM (1982) Gaucher's disease associated with chronic lymphocytic leukemia. South Med J 75:361-363

16. Marti GE, Ryan ET, Papadopoulos NM et al (1988) Polyclonal Bcell lymphocytosis and hypergammaglobulinemia in patients with Gaucher disease. Am J Hematol 29:189-194

17. Petrides PE, leCoutre P, Muller-Hocker J et al (1998) Coincidence of Gaucher's disease due to a private mutation and $\mathrm{Ph}^{\prime}$ positive chronic myeloid leukemia. Am J Hematol 59:87-90

18. Pinkhas J, Djaldetti M, Yaron M (1965) Coincidence of multiple myeloma with Gaucher's disease. Isr J Med Sci 1:537-540

19. Pratt PW, Kochwa S, Estren S (1968) Immunoglobulin abnormalities in Gaucher's disease. Report of 16 cases. Blood 31:633-640

20. Ruestow PC, Levinson DJ, Catchatourian R et al (1980) Coexistence of IgA myeloma and Gaucher's disease. Arch Intern Med 140:1115-1116

21. Shoenfeld Y, Gallant LA, Shaklai M et al (1982) Gaucher's disease: a disease with chronic stimulation of the immune system. Arch Pathol Lab Med 106:388-391

22. Turesson I, Rausing A (1975) Gaucher's disease and benign monoclonal gammopathy. A case report with immunofluorescence study of bone marrow and spleen. Acta Med Scand 197:507-512

23. Dispenzieri A, Gertz MA, Therneau TM, Kyle RA (2001) Retrospective cohort study of 148 patients with polyclonal gammopathy. Mayo Clin Proc 76:476-487

24. Kyle RA, Therneau TM, Rajkumar SV et al (2006) Prevalence of monoclonal gammopathy of undetermined significance. N Engl J Med 354:1362-1369

25. Lee RE (1982) The pathology of Gaucher disease. Prog Clin Biol Res 95:177-217

26. de Fost M, Vom DS, Weverling GJ et al (2006) Increased incidence of cancer in adult Gaucher disease in Western Europe. Blood Cells Mol Dis 36:53-58

27. Rosenbloom BE, Weinreb NJ, Zimran A et al (2005) Gaucher disease and cancer incidence: a study from the Gaucher Registry. Blood 105:4569-4572

28. Shiran A, Brenner B, Laor A, Tatarsky I (1993) Increased risk of cancer in patients with Gaucher disease. Cancer 72:219-224

29. Zimran A, Liphshitz I, Barchana M, Abrahamov A, Elstein D (2005) Incidence of malignancies among patients with type I 
Gaucher disease from a single referral clinic. Blood Cells Mol Dis 34:197-200

30. Barak V, Acker M, Nisman B et al (1999) Cytokines in Gaucher's disease. Eur Cytokine Netw 10:205-210

31. Hollak CE, Evers L, Aerts JM, van Oers MH (1997) Elevated levels of M-CSF, sCD14 and IL8 in type 1 Gaucher disease. Blood Cells Mol Dis 23:201-212

32. Lichtenstein M, Zimran A, Horowitz M (1997) Cytokine mRNA in Gaucher disease. Blood Cells Mol Dis 23:395-401

33. Michelakakis H, Spanou C, Kondyli A et al (1996) Plasma tumor necrosis factor-a (TNF-a) levels in Gaucher disease. Biochim Biophys Acta 1317:219-222

34. Borset M, Lien E, Espevik T et al (1996) Concomitant expression of hepatocyte growth factor/scatter factor and the receptor c-MET in human myeloma cell lines. J Biol Chem 271:24655-24661

35. Boot RG, Verhoek M, de Fost M et al (2004) Marked elevation of the chemokine CCL18/PARC in Gaucher disease: a novel surrogate marker for assessing therapeutic intervention. Blood 103:33-39

36. Deibener J, Kaminsky P, Jacob C et al (1998) Enzyme replacement therapy decreases hypergammaglobulinemia in Gaucher's disease. Haematologica 83:479-480

37. Bradwell AR, Carr-Smith HD, Mead GP et al (2001) Highly sensitive, automated immunoassay for immunoglobulin free light chains in serum and urine. Clin Chem 47:673-680

38. Drayson M, Tang LX, Drew R et al (2001) Serum free light-chain measurements for identifying and monitoring patients with nonsecretory multiple myeloma. Blood 97:2900-2902

39. Katzmann JA, Clark RJ, Abraham RS et al (2002) Serum reference intervals and diagnostic ranges for free kappa and free lambda immunoglobulin light chains: relative sensitivity for detection of monoclonal light chains. Clin Chem 48:1437-1444

40. Katzmann JA, Abraham RS, Dispenzieri A, Lust JA, Kyle RA (2005) Diagnostic performance of quantitative kappa and lambda free light chain assays in clinical practice. Clin Chem 51:878-881

41. Rajkumar SV, Kyle RA, Therneau TM et al (2005) Serum free light chain ratio is an independent risk factor for progression in monoclonal gammopathy of undetermined significance. Blood 106:812-817

42. Abadie JM, Bankson DD (2006) Assessment of serum free light chain assays for plasma cell disorder screening in a Veterans Affairs population. Ann Clin Lab Sci 36:157-162

43. Daniels LB, Glew RH (1982) beta-Glucosidase assays in the diagnosis of Gaucher's disease. Clin Chem 28:569-577
44. Hollak CE, Aerts JM, Goudsmit R et al (1995) Individualised low-dose alglucerase therapy for type 1 Gaucher's disease. Lancet 345:1474-1478

45. Zimran A, Kay A, Gelbart T et al (1992) Gaucher disease. Clinical, laboratory, radiologic, and genetic features of 53 patients. Medicine (Baltimore) 71:337-353

46. Criteria for the classification of monoclonal gammopathies, multiple myeloma and related disorders: a report of the International Myeloma Working Group. Br J Haematol. 2003;121: 749-757

47. Durie BG, Salmon SE (1975) A clinical staging system for multiple myeloma. Correlation of measured myeloma cell mass with presenting clinical features, response to treatment, and survival. Cancer 36:842-854

48. Greipp PR, San Miguel J, Durie BG et al (2005) International staging system for multiple myeloma. J Clin Oncol 23:34123420

49. Hollak CE, van Weely S, van Oers MH, Aerts JM (1994) Marked elevation of plasma chitotriosidase activity. A novel hallmark of Gaucher disease. J Clin Invest 93:1288-1292

50. Grosbois B, Jego P, de Rosa H et al (1997) Triclonal gammopathy and malignant immunoproliferative syndrome. Rev Med Interne $18: 470-473$

51. Hughes D, Cappellini MD, Berger M et al (2007) Recommendations for the management of the haematological and oncohaematological aspects of Gaucher disease. Br J Haematol 138 (6):676-686

52. Altarescu G, Phillips M, Foldes AJ et al (2003) The interleukin-6 promoter polymorphism in Gaucher disease: a new modifier gene? QJM 96:575-578

53. Gery I, Zigler JS Jr., Brady RO, Barranger JA (1981) Selective effects of glucocerebroside (Gaucher's storage material) on macrophage cultures. J Clin Invest 68:1182-1189

54. Mizukami H, Mi Y, Wada R et al (2002) Systemic inflammation in glucocerebrosidase-deficient mice with minimal glucosylceramide storage. J Clin Invest 109:1215-1221

55. Boven LA, van Meurs M, Boot RG et al (2004) Gaucher cells demonstrate a distinct macrophage phenotype and resemble alternatively activated macrophages. Am J Clin Pathol 122: 359-369

56. Altarescu G, Zimran A, Michelakakis H, Elstein D (2005) TNFalpha levels and TNF-alpha gene polymorphism in type I Gaucher disease. Cytokine 31:149-152 